\title{
Article
}

\section{Advances in chemometric control of commercial diesel adulteration by kerosene using IR spectroscopy}

Moura, Heloise O.M.A., Camara, Anne B.F., Santos, Marfan, Medeiros-De-morais, Camilo De lelis, de Lima, Leomir A.S., Lima, Kassio M.G. and de Carvalho, Luciene S.

Available at http://clok.uclan.ac.uk/28412/

Moura, Heloise O.M.A., Camara, Anne B.F., Santos, Marfan, Medeiros-Demorais, Camilo De lelis ORCID: 0000-0003-2573-787X, de Lima, Leomir A.S., Lima, Kassio M.G. and de Carvalho, Luciene S. (2019) Advances in chemometric control of commercial diesel adulteration by kerosene using IR spectroscopy. Analytical and Bioanalytical Chemistry . ISSN 1618-2642

It is advisable to refer to the publisher's version if you intend to cite from the work. http://dx.doi.org/10.1007/s00216-019-01671-y

For more information about UCLan's research in this area go to

http://www.uclan.ac.uk/researchgroups/ and search for <name of research Group>.

For information about Research generally at UCLan please go to http://www.uclan.ac.uk/research/

All outputs in CLoK are protected by Intellectual Property Rights law, including Copyright law. Copyright, IPR and Moral Rights for the works on this site are retained by the individual authors and/or other copyright owners. Terms and conditions for use of this material are defined in the policies page. 


\section{kerosene using IR spectroscopy}

${ }^{1}$ Post-Graduation Program in Chemistry, Federal University of Rio Grande do Norte, 59078-900, Natal, BR.

${ }^{2}$ School of Pharmacy and Biomedical Sciences, University of Central Lancashire, Preston PR1 2HE, UK.

$10 \quad$ \#E-mail address: helo.medeiros@outlook.com

11 "E-mail address: luciene_car@hotmail.com

12

13

14

15

16

17

18

19

20

21

22 


\section{Abstract}

27 Adulteration is a recurrent issue found in fuel screening. Commercial diesel contamination by kerosene is highly

28 difficult to be detected via physicochemical methods applied in market. Although the contamination may affect

29 diesel quality and storage stability, there is a lack of efficient methodologies for this evaluation. This paper assessed

30 the use of IR spectroscopies (MIR and NIR) coupled with partial least squares (PLS) regression, support vectors

31 machine regression (SVR) and multivariate curve resolution with alternating least squares (MCR-ALS) calibration

32 models for quantifying and identifying the presence of kerosene adulterant in commercial diesel. Moreover,

33 principal component analysis (PCA), successive projections algorithm (SPA) and genetic algorithm (GA) tools

34 coupled to linear discriminant analysis were used to observe the degradation behavior of 60 samples of pure and

35 kerosene-added diesel fuel in different concentrations over 60 days of storage. Physicochemical properties of

36 commercial diesel with $15 \%$ kerosene remained within conformity with Brazilian screening specifications; in

37 addition, specified tests were not able to identify changes in the blends' performance over time. By using

38 multivariate classification, the samples of pure and contaminated fuel were accurately classified by aging level into

39 two well-defined groups, and some spectral features related to fuel degradation products were detected. PLS and

40 SVR were accurate to quantify kerosene in the $2.5-40 \%(\mathrm{v} / \mathrm{v})$ range, reaching RMSEC $<2.59 \%$ and RMSEP $<5.56 \%$,

41 with high correlation between real and predicted concentrations. MCR-ALS with correlation constraint was able to

42 identify and recover the spectral profile of commercial diesel and kerosene adulterant from the IR spectra of

43 contaminated blends.

44 Keywords: Diesel fuel, Adulteration, Kerosene, Multivariate analysis, Storage stability.

45

46

47

48

49

50

51

52

53 


\section{Introduction}

55 An increase in energy and fuel consumption worldwide has encouraged researchers to study new energy sources and

56 look for the best ways to use them. Nowadays, the most important problem faced in the fuel screening field is

57 adulteration, which occurs during the route between the refinery and gas stations to provide illegal profit to

58 scammers [1,2]. In Brazil, gasoline adulteration is currently well controlled in the Fuel Quality Monitoring Program

59 (PMQC) founded by the National Agency of Petroleum, Natural Gas and Biofuels (ANP), using specific analysis of

60 markers added to solvents that can be used as contaminants [3]; however, there is no specific methodology for

61 detecting adulterants in diesel, which is the most consumed fuel in the country [4,5].

62 Biodiesel, kerosene and vegetable oils are the main adulterants of diesel reported in literature due to its

63 affordability and lower cost in comparison to the original fuel [6]. Biodiesel is a renewable fuel composed of esters

64 that is blended into Brazilian diesel $(10 \% \mathrm{v} / \mathrm{v})$ due to ANP requirements for reducing the emission of harmful gases,

65 but scammers have illegally added a greater amount of biodiesel due to its cheaper production [7]. Kerosene solvent

66 is a cheap petroleum distillate that has similar hydrocarbon composition to diesel and is widely used for adulteration,

67 making it practically impossible to detect this contaminant via physicochemical property tests and other univariate

68 methods [8].

69 Fuel contamination can cause many problems to burning and storage quality, with the latter being directly 70 associated with the oxidative stability of fuel and signifies how much they resist degradation processes. Diesel and 71 mainly biodiesel components are susceptible to oxidation and hydrolysis reactions over time; thus, the composition 72 of the fuel blend changes over time and the presence of an uncontrolled substance used for adulteration can exert 73 some influence on the process, affecting its quality due to aging [9]. Despite this, ANP specifications do not regulate 74 tests to observe the degradation level of commercial diesel over time due to the lack of a methodology that performs 75 efficient quality screening of this parameter during fuel storage [5]. Therefore, mathematical tools provided by 76 chemometrics enable analyzing multivariate results generated by simple techniques such as infrared (IR) 77 spectroscopy in a way that statistical methods for univariate systems may be inadequate, with accurate, fast and 78 detailed responses [10,11].

79 Principal component analysis (PCA), successive projections algorithm (SPA) and genetic algorithm (GA) are 80 techniques that promote intelligent experimental data reduction. PCA reduces data to principal components, while 81 SPA and GA reduce it to selected variables. This procedure can improve the potential of the supervised linear 
82 discriminant analysis (LDA) for discriminating the samples in their respective classes due to the lower data 83 complexity. The combinations PCA-LDA, SPA-LDA and GA-LDA are often used in combination for a wide range 84 of applications [12-15], but their potential is not widely explored for screening diesel quality [16].

85 In case of quantifying kerosene into commercial diesel fuel, the use of a calibration model capable to deal efficiently with non-linear relationships and high dimensional input vectors as support vectors machine regression

87 (SVR) is crucial, since the widely used partial least squares (PLS) has limited performance with complex systems 88 [17]. A promising tool for analyzing fuel adulteration is the multivariate curve resolution with alternating least squares (MCR-ALS). This technique stands out due to its capability to quantify and identify the analyte in the

90 presence of interferences in samples, since these interferences are presented in the calibration samples [18]. In 91 addition, this technique presents some advantages in relation to PLS, such as the smaller number of samples needed 92 and the capacity to quantify and identify interferences (adulterants) in samples without previous knowledge of them, 93 which can be called "second order advantage" [19].

94 This paper evaluates the efficiency of multivariate tools to solve important issues in diesel screening using NIR 95 and MIR spectroscopies. PLS, SVR and MCR-ALS were applied to quantify and identify the presence of kerosene 96 adulterant in commercial diesel. PCA-LDA, SPA-LDA and GA-LDA models were used to classify and observe the 97 degradation behavior of pure and kerosene-added diesel fuel samples in different concentrations over 60 days of 98 storage. Oxidative stability analysis were performed by PetroOxy accelerated oxidation method to compare with the 99 classification results, in addition to atmospheric distillation, crystallization, specific mass and viscosity tests 100 specified by ANP.

\section{Materials and Methods}

\section{Sample Preparation}

104 Diesel S10B10 samples with 10\% (v/v) of Brazilian commercial biodiesel (soybean oil biodiesel) and $10 \mathrm{mg} \mathrm{kg}^{-1}$ 105 sulfur were kindly donated by Clara Camarão Potiguar Refinery (RPCC) and mixed up to different concentrations of 106 commercial kerosene solvent at the Energetic Technology Laboratory (LTEN) for simulating the adulteration 107 process. The samples were divided in two datasets. In the first one, which involves classification models, were used 108 concentrations in the range 5 to $25 \%(\mathrm{v} / \mathrm{v})$, with increments of $2.5 \%(\mathrm{v} / \mathrm{v})$ and precision of $0.05 \%$. Each blend was 109 divided into six parts of the same volume and placed in six different amber flasks, making a total of sixty samples. 
110 All flasks were encoded, sealed and stored in a closed box at room temperature for sixty days, along with samples of

111 pure S10B10. Six analysis periods were defined for monitoring physicochemical properties and MIR/NIR features

112 of the mixtures during storage, namely days 0 (beginning of storage), 7, 15, 30, 45 and 60.

113 For the second dataset, used for adulterant quantification with regression methods such as PLS, SVR and MCR-

114 ALS were produced 16 samples ranging from 2.5 to $40 \%(\mathrm{v} / \mathrm{v})$. MIR and NIR spectra were recorded for modeling.

\section{Physicochemical Analysis}

117 All samples were submitted to MIR and NIR analysis on monitoring days, but only the pure S10B 10 and $15 \%$

118 kerosene (Q0 and Q15) samples had some of their physicochemical properties evaluated in order to observe possible 119 changes in composition and properties as a result of the added kerosene and/or storage time. Table 1 shows the 120 reference methods of specified ANP physicochemical analysis, in addition to oxidative stability PetroOXY test, 121 employed for monitoring samples Q0 and Q15 following regulations determined by ASTM International. In addition, 122 some properties inferred for diesel S10B10 and kerosene solvent are depicted.

124 Table 1. Physicochemical analysis and ASTM standards used in this work.

\begin{tabular}{cccc}
\hline Analysis & Diesel S10B10 & $\begin{array}{c}\text { Commercial kerosene } \\
\text { solvent }\end{array}$ & Standard [20-23] \\
\hline $\begin{array}{c}\text { PetroOXY induction period (IP) } \\
(\text { min) }\end{array}$ & 60.0 & - & ASTM D7545 \\
$\begin{array}{c}\text { Atmospheric distillation }\left({ }^{\circ} \mathrm{C}\right): \\
10 \% \text { distillate } \\
50 \% \text { distillate }\end{array}$ & 192.9 & - & ASTM D86 \\
$\begin{array}{c}\text { Kinematic viscosity at } 40{ }^{\circ} \mathrm{C} \\
\left(\mathrm{mm}^{2} / \mathrm{s}\right)\end{array}$ & 281.1 & & \\
$\begin{array}{c}\text { Specific mass at } 20{ }^{\circ} \mathrm{C}\left(\mathrm{kg} / \mathrm{m}^{3}\right) \\
\text { Cloud point }\left({ }^{\circ} \mathrm{C}\right)\end{array}$ & 828.0 & 786.0 & ASTM D7042 \\
& 0.40 & - & ASTM D7042 \\
\hline
\end{tabular}

\section{Spectral Data Analysis}

128 MIR measurements were carried out on a Shimadzu IRAffinity-1 spectrometer equipped with an attenuated total 129 reflectance (ATR) sample holder and $\mathrm{ZnSe}$ crystal. The results were obtained in a wavenumber range from 700- 
$1304000 \mathrm{~cm}^{-1}$ with resolution of $4 \mathrm{~cm}^{-1}$ and 32 scans. NIR data were obtained using a spectrometer from ARCoptix with 131 a quartz cuvette of $1.00 \mathrm{~mm}$ in transmission mode. The NIR readings were performed using ARCspectro software 132 version 1.6 in a wavelength range from 1000-2500 nm and resolution of $8 \mathrm{~nm}$.

133 Data pre-treatment and construction of the classification and calibration models were performed using MATLAB 134 R2012b software (MathWorks Inc., Natick, USA) with PLS Toolbox version 7.9.3 (Eigenvector Research, Inc., 135 Manson, USA). For the development of multivariate models, baseline correction, Savitzky-Golay smoothing 136 (window of 15 points) and mean center were performed on the MIR spectra dataset for denoising; whereas the NIR 137 data were pre-processed by using multiplicative scatter correction (MSC), Savitzky-Golay smoothing (window of 15 138 points) and mean center.

139 Before modeling, spectral data were divided into training (70\%), validation (15\%) and prediction (15\%) sets for 140 applying LDA to PCA, SPA and GA scores; and calibration (70\%) and prediction (30\%) sets for PLS regression, by 141 applying the classic Kennard-Stone (KS) uniform sampling selection algorithm [24]. Cross-validation "leave-one142 out" was used for PLS. The overall methodology developed in this research is depicted in Scheme 1.

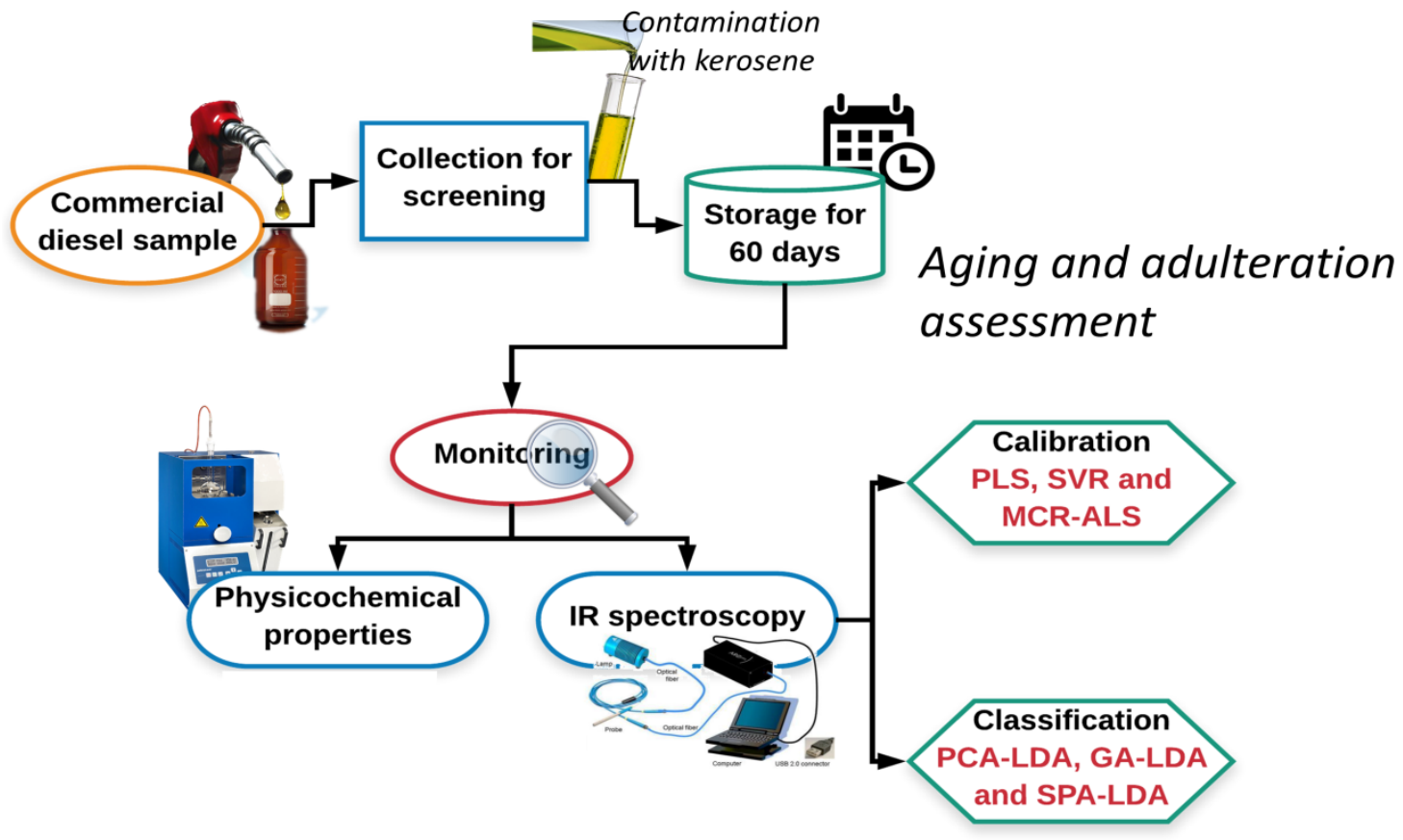

144 Scheme 1. Process flow diagram of the methodology used in this work.

\section{Chemometric Methods}

147 Exploratory Analysis (PCA) and Variable Selection Methods (SPA and GA) 
148 Principal component analysis (PCA) is an unsupervised classification method that decomposes a data set into 149 orthogonal variables called principal components (PCs). This reduces the size of the data while retaining the 150 variance in the data set [25]. PCA is calculated based on the maximum variance contained in the dataset in a 151 descending order of importance, where the first PC contains the larger explained variance, followed by the second, 152 and so on. In addition, PCA solves collinearity problems to reduce the data size and improves efficacy to highlight 153 and visualize the variations and heterogeneities among the samples. The PCA decomposition takes the form of [26]:

$154 \quad \mathrm{X}=\mathrm{TP}^{\mathrm{T}}+\mathrm{E}$

155 where $\mathrm{X}$ is the spectral data set with $\mathrm{n}$ rows (samples) and $\mathrm{m}$ columns (wavelengths); $\mathrm{T}$ are the scores for all 156 principal components a $(\mathrm{a}=1,2,3, \ldots, \mathrm{A})$, with size of $\mathrm{n}$ rows and $\mathrm{A}$ columns; $\mathrm{P}$ are the loadings for all principal 157 components a, with size of $\mathrm{m}$ rows and A columns; and $\mathrm{E}$ is the residual matrix.

158 Successive projection algorithm (SPA) and genetic algorithm (GA) are techniques used as variables selection. 159 SPA is a technique that considers each spectral variable as a vector. In this analysis, an initial vector (initial variable)

160 is used. Then, new vectors with their respective projections are added in a subset orthogonal to that initial vector. In 161 this way, the SPA selects those variables with more differentiated projections. With this, collinearity problems are 162 eliminated [27]. GA, on the other hand, has a process that mimics the principle of Darwin's theory of evolution. In 163 this technique, a population of variables is chosen randomly. This population is composed of subsets of variables. 164 For each subset a fitness value is assigned through the fitness function present in the GA routine. Based on this 165 fitness the subsets of variables can be eliminated or "survived" in a step called selection. Then, the genetic operators 166 mutation and crossover are triggered, where initially selected variables may become unselected (mutation) and 167 characteristics of one subset can pass to another (crossover). This procedure is called generation. There are as many 168 generations as requested, and finally, the best fit subset will be the one with the selected variables [28]. The 169 reduction of the multicollinearity problems obtained by SPA is done through the minimum of the cost function G.

170 The fitness of GA is also calculated with this function, but in this case the fitness is calculated as the inverse of the 171 cost function $\mathrm{G}$, which is defined as:

$172 \quad G=\frac{1}{N_{v}} \sum_{N=1}^{N_{v}} g_{n}$

173 with $\mathrm{g}_{\mathrm{n}}$ being described as:

$174 \quad g_{n}=\frac{r^{2}\left(x_{n}, m_{l(n)}\right)}{\min _{l(m) \neq l(n)} r^{2}\left(x_{n}, m_{l(m)}\right)}$ 
175 where the numerator is the square of the Mahalanobis distance between the object $\mathrm{x}_{\mathrm{n}}$ of the class $1_{(\mathrm{n})}$ and the mean of 176 its true class $\mathrm{m}_{l(\mathrm{n})}$; and the denominator is the square of the Mahalanobis distance between the object $\mathrm{x}_{\mathrm{n}}$ and the 177 center of the nearest wrong class.

179 Linear Discriminant Analysis (LDA)

180 Linear discriminant analysis (LDA) is a supervised classification technique that improves the segregation level and 181 reveals clusters that are maximized based on the separation between multiple classes rather than variations within 182 each group [29]. Since PCA, SPA and GA are exploratory analysis methods, they are only able to show a 183 distribution pattern between samples. On the other hand, LDA is a supervised classification method capable of 184 making an exact differentiation between the different data groups. Thus, the scores are utilized as discriminant 185 variables for LDA technique in order to create a linear decision boundary between them [30]. The LDA 186 classification score takes the form of:

$187 \operatorname{cf}\left(\mathrm{x}_{i}\right)=\left(\mathrm{x}_{i}-\mu_{k}\right)^{\mathrm{T}} \Sigma_{\text {pooled }}^{-1}\left(\mathrm{x}_{i}-\mu_{k}\right)-2 \ln \pi_{k}$

188 where $\mathbf{x}_{i}$ is the measurement vector of sample $i ; \mu_{k}$ is the mean of class $k ; \Sigma_{\text {pooled }}$ is the pooled covariance matrix; and $189 \pi_{k}$ is the prior probability of class $k$. These parameters are calculated as [30]:

$190 \mu \mathrm{k}=1 \mathrm{nki}=1 \mathrm{nkxi}$

$191 \quad \Sigma_{\text {pooled }}=\frac{1}{n} \sum_{k=1}^{K} n_{k} \Sigma_{k}$

$192 \quad \Sigma_{k}=\frac{1}{n_{k}-1} \sum_{i=1}^{n_{k}}\left(\mathrm{x}_{i}-\mu_{k}\right)\left(\mathrm{x}_{i}-\mu_{k}\right)^{\mathrm{T}}$

$193 \pi_{k}=\frac{n_{k}}{n}$

194 where $\Sigma_{\mathrm{k}}$ is the variance covariance matrix of class $\mathrm{k} ; \mathrm{n}_{\mathrm{k}}$ is the number of samples of class $\mathrm{k} ; \mathrm{n}$ is the total number of 195 samples in the training set; and $\mathrm{K}$ is the number of classes.

\section{Calibration Models}

198 Partial least squares (PLS) regression is a multivariate calibration technique that finds factors (latent variables, LVs) 199 in the spectra set that explain its maximum variance by using the simultaneous decomposition of the spectral and 200 concentration matrices. The spectra set $\mathrm{X}$ and the concentration set $\mathrm{y}$ are decomposed as follows [31]:

$201 \quad \mathrm{X}=\mathrm{TP}^{\mathrm{T}}+\mathrm{E}$ 
203 where $\mathrm{T}$ is the scores matrix of $\mathrm{X}$; $\mathrm{P}$ is the loadings matrix of $\mathrm{X}$; $\mathrm{E}$ is the residual matrix of $\mathrm{X}$; $\mathrm{U}$ is the scores matrix 204 of $\mathrm{y} ; \mathrm{q}$ is the loading vector of $\mathrm{y}$; and $\mathrm{f}$ is the residual vector of $\mathrm{y}$.

205 Support vector machines (SVM) is a supervised learning algorithm employed for training a computational system to recognize patterns and to perform further predictions. SVM for regression, called support vector regression (SVR)

207 [32], is commonly employed in calibration problems for quantification purposes. SVR is based on estimating a 208 response function for each sample spectrum as [33]:

$209 \mathrm{f}(\mathrm{x})=\mathrm{W} \varnothing(\mathrm{x})+\mathrm{b}$

210 where the sample spectrum $x$ is non-linear mapped into a high-dimensional feature space $\mathbf{Z}$ by $W \emptyset(x)$, in which $211 \emptyset: x_{i} \rightarrow z_{i}$; and $b$ represents the bias parameters.

212 Multivariate curve resolution with alternating least squares (MCR-ALS) is a bilinear model that is the multi213 wavelength extension from Lambert-Beer's law, and can be described by Equation 12 [34]:

$214 \quad \mathrm{D}=\mathrm{CS}^{\mathrm{T}}+\mathrm{E}$

215 where $\mathrm{D}(n \times m)$ is a data matrix containing the NIR or FTIR spectra of $n$ samples for the $m$ recorded wavelengths;

$216 \mathrm{C}(n \times A)$ and $\mathrm{S}^{\mathrm{T}}(A \times m)$ are the matrices with the concentration and spectra profiles of $A$ pure components in the 217 samples, respectively. E has the same size as D and contains the unexplained variance from the bilinear model, 218 related as the experimental error [35].

219 Some constraints must be applied to each iteration to reduce the number of possible solutions for $\mathrm{C}$ and $\mathrm{S}^{\mathrm{T}}$, and to 220 give chemical meaning to the results. Non-negativity constraint was applied in this work. This constraint forces the 221 concentration and/or spectral profile to be equal or larger than zero [36]. The correlation constraint allows the 222 construction of a model with a univariate internal calibration from the scores calculated by MCR against the 223 reference values concentration, being able to predict the concentration of calibration and unknown samples, and the 224 concentration of these samples has to be in the analytical range of the calibration set [18].

\section{Figures of Merit (FOMs)}

227 In order to evaluate the predictive capacity and accuracy of multivariate calibration and classification models, a set 228 of figures of merit was calculated (Table 2) [37]. 
Table 2. Equations for calculating FOMs.

\begin{tabular}{|c|c|}
\hline \multicolumn{2}{|c|}{ Calibration } \\
\hline Root mean square error of prediction (RMSEP) & $R M S E P=\sqrt{\frac{\sum_{i=1}^{n}\left(y_{i}-\hat{y}_{i}\right)^{2}}{n}}$ \\
\hline Standard error of prediction (SEP) & $S E P=\sqrt{\frac{\sum_{i=1}^{n}\left(y_{i}-\hat{y}_{i}\right)^{2}}{n}}$ \\
\hline Bias & bias $=\frac{2_{i=1}^{n}\left(y_{i}-\hat{y}_{i}\right)}{n}$ \\
\hline $\begin{array}{l}\text { Relative percentage error in concentration } \\
\text { prediction }\left(\mathrm{RE}_{\mathrm{F}} \%\right)\end{array}$ & $R E(\%)=100 \sqrt{\frac{\sum_{i-1}^{n}\left(y_{i}-\hat{y}_{i}\right)^{2}}{\sum_{i=1}^{n} y_{i}^{2}}}$ \\
\hline $\begin{array}{l}\text { Root mean square error of cross-validation } \\
\qquad \text { (RMSECV), }\end{array}$ & RMSECV $=\sqrt{\frac{\sum_{i=1}^{n}\left(y_{p}-y_{e}\right)^{2}}{n}}$ \\
\hline \multicolumn{2}{|c|}{ Classification } \\
\hline Sensitivity (SENS) & $\operatorname{SENS}(\%)=\frac{T P}{T P+F N} \times 100$ \\
\hline Specificity (SPEC) & $\operatorname{SPEC}(\%)=\frac{T N}{T N+F P} \times 100$ \\
\hline Correct classification (CC) & $C C(\%)=\frac{\left\{\sum y_{1}+\sum y_{2}\right\}}{n} \times 100$ \\
\hline
\end{tabular}

$n$ : total number of samples in the set; $y_{j}$ and $\hat{y}_{\mathrm{i}}$ : actual and predicted concentrations in sample $I_{j} y_{2}$ and $y_{\varepsilon}$ : predicted and expected concentration values; FN: false negative; FP: false positive; TP: true positive; TN: true negative; $y_{l}$ and $y_{2}$ : number of samples incorrectly classified for each class.

\section{Results and Discussion}

\section{Physicochemical Analysis}

235 Fig. 1 depicts the results for the physicochemical evaluations. The distillation curves of samples with 0 and $15 \%$ 236 kerosene performed on storage days 0 and 60 are indicated by Q0-0 and Q15-0 (Fig. 1a), Q0-60 and Q15-60 (Fig.

237 1b). Atmospheric distillation is one of the most important physicochemical properties to detect fuel adulteration in 238 Brazil, and is based on the boiling temperature profile of the sample components [6]. Although the insertion of 239 kerosene caused a slight decrease in boiling points of the intermediary hydrocarbon fraction of the blends, the 240 temperatures obtained were still in accordance with ANP specifications for commercial diesel [5] and did not 241 change over storage time. 

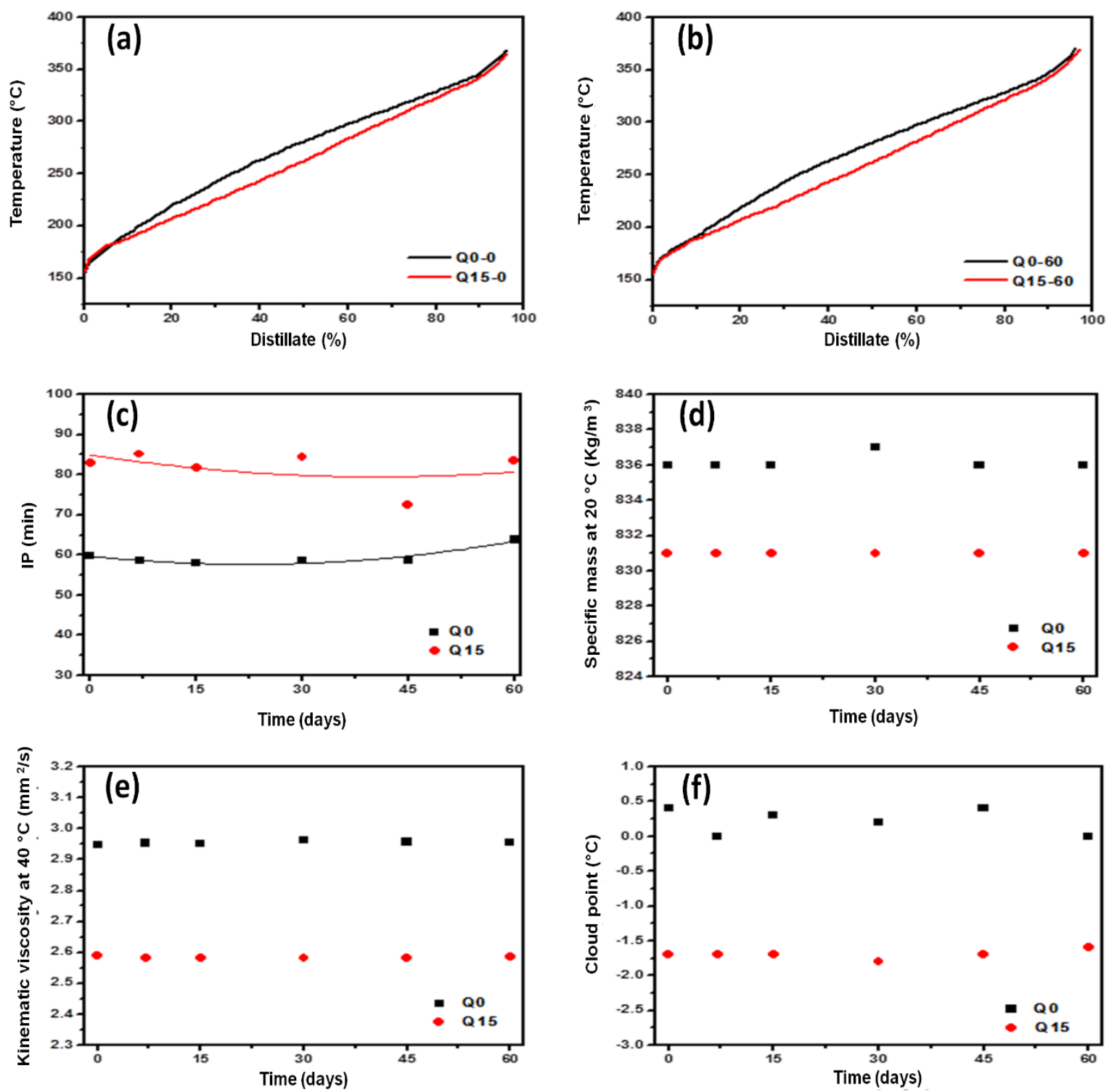

243 Fig. 1. Results for (a and b) atmospheric distillation, (c) PetroOxy, (d) specific mass at $20{ }^{\circ} \mathrm{C}$, (e) kinematic

244 viscosity at $40{ }^{\circ} \mathrm{C}$ and (f) cloud point tests for Q0 and Q15 samples during storage.

The induction period (IP) of Q0 and Q15 blends (Fig. 1c) remained within a range of little variability between

247 days 0 and 60 [38]. The addition of $15 \%$ kerosene to S10B 10 diesel increased the IP of the mixtures, probably due to

248 the initial dilution of biodiesel in the S10B10 mixture, thus reducing the number of unsaturated molecules and ester

249 groups available to react and form oxidized by-products [39]. The decrease in specific mass at $20{ }^{\circ} \mathrm{C}$ and kinematic

250 viscosity at $40{ }^{\circ} \mathrm{C}$ values (Fig. 1d and 1e) with kerosene contamination is an effect of its relatively lighter

251 composition in comparison to diesel, and promoting the dilution of denser and more viscous diesel-biodiesel 
components [40]. The cloud point of the mixtures also decreased after adding kerosene (Fig. 1f) by simply diluting

253 the paraffin waxes and biodiesel ester chains [41,42].

254 According to the results shown above in Fig. 1, none of the physicochemical properties evaluated in this work 255 were able to detect changes in the characteristics of the diesel-biodiesel blends, either pure or kerosene, during storage. In addition, the contaminated diesel S10B10 samples remained within the quality parameters of ANP

257 Resolution $\mathrm{N}^{\circ} 30$ and the adulteration would easily go unnoticed by a common physicochemical evaluation. Thus, 258 chemometric tools were applied to IR data for elucidating these issues.

\section{Infrared Spectroscopy}

261 The spectra obtained by MIR and NIR analysis for samples with 0 to $40 \%$ (v/v) kerosene on the initial day of 262 storage are shown in Fig. 2a and 2b, respectively.
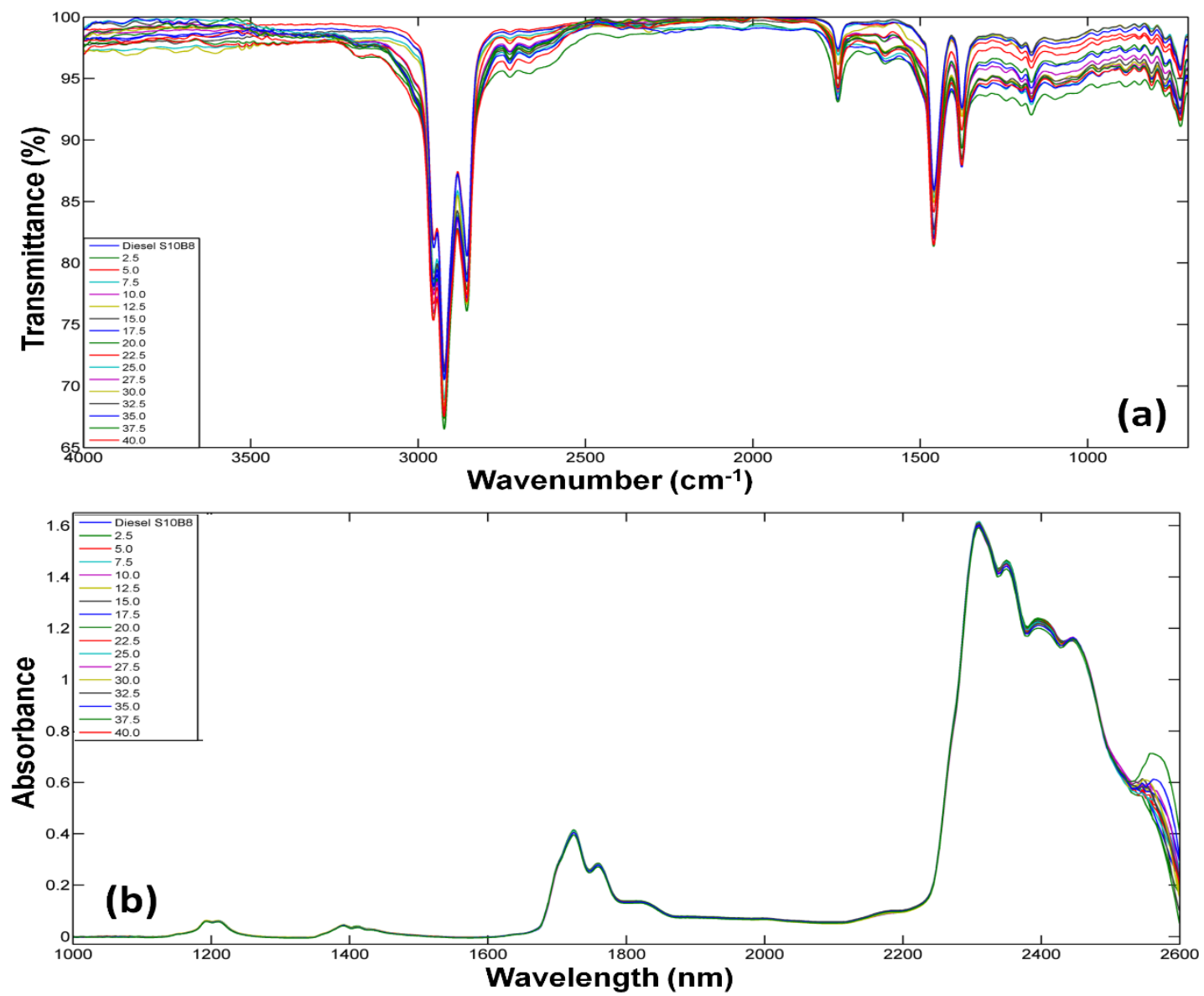

265 Fig. 2. (a) MIR and (b) NIR spectra for samples with 0 to $40 \%$ (v/v) kerosene on the first day of storage. 
In the IR spectra (Fig. 2) there is the presence of some characteristic absorption features of biodiesel and the petroleum distillates. For MIR (Fig. 2a), the bands at 2952-2853 $\mathrm{cm}^{-1}$ are related to anti-symmetric and symmetrical stretching modes of $\mathrm{CH}_{2}, \mathrm{CH}_{3}$ and $\mathrm{CH}$ biodiesel chains. The absorption feature at $1740 \mathrm{~cm}^{-1}$ refers to $\mathrm{C}=\mathrm{O}$ stretching mode of saturated aliphatic esters, and those occurring at 1196 and $1168 \mathrm{~cm}^{-1}$ correspond to the C-O stretching mode of esters from the biodiesel. The bands at $1461 \mathrm{~cm}^{-1}, 1377 \mathrm{~cm}^{-1}$ and $722 \mathrm{~cm}^{-1}$ are referent to angular C-H bond 271 deformations [43].

272 There are bands at $2130 \mathrm{~nm}$ and $2375 \mathrm{~nm}$ in the NIR spectra (Fig. 2b) referent to combination C-H/C=O stretching and C-H deformation bands, and a C-H stretch/C-C stretching combination band, respectively. In addition,

274 there are band suppressions at $1690-1800 \mathrm{~nm}, 2150 \mathrm{~nm}, 2400 \mathrm{~nm}$ and $2450 \mathrm{~nm}$, referent to the $1^{\text {st }}$ overtone of $\mathrm{CH}_{2}$

275 symmetric stretching, combination $\mathrm{C}-\mathrm{H}$ stretching/C=O stretching, combination $\mathrm{C}-\mathrm{H}$ stretching/C-C stretching 276 forming $\mathrm{CH}$, and combination $\mathrm{C}-\mathrm{H}$ stretching/C-C stretching forming $\mathrm{CH}_{2}$, respectively [44].

277 Although the increase of kerosene content in the samples promotes the biodiesel dilution (as can be seen in Fig.

278 A1 of Online Resource 1), it does not linearly alter the intensity of the ester fingerprint region bands (2130 nm for 279 NIR, $1740 \mathrm{~cm}^{-1}$ for MIR), thus precluding univariate quantification.

\section{Multivariate Calibration for Kerosene Quantification}

282 As spectroscopic techniques do not resolve the components in a sample, chemical information about single 283 components is embedded in multiple bands in the spectra and spectroscopic instruments alone provide very limited 284 information toward unambiguous identification of unknown mixtures [6,45]. In this case, chemometric tools are 285 commonly employed.

286 PLS regression was applied to the data using 4 LVs (99.94\% explained variance) for MIR and 4 LVs (99.99\% 287 explained variance) for NIR data. SVR calibration models were obtained using 9 support vectors (SVs) for NIR and $28811 \mathrm{SV}$ for MIR. Thus, the SVR model was obtained using $C$ (100), $m$ (0.01) and Gamma (10) parameters, for both 289 techniques, in order to find the best RMSEC value. The use of adequate parameters allows the adjustment of the $e$ 290 insensitive loss function and the $e$-tube, which prevents the model from overfitting [33]. The measured versus 291 predicted concentration of kerosene (\%) plots of PLS and SVR calibration models are found in the Online Resource 292 1. Results for FOMs are depicted in Table 3. 
294 Table 3. Figures of merit (FOMs) for PLS and SVR calibration models.

\begin{tabular}{|c|c|c|c|c|c|c|c|}
\hline Model & FOM & \multicolumn{3}{|c|}{ MIR } & \multicolumn{3}{|c|}{ NIR } \\
\hline \multirow[t]{7}{*}{ PLS } & & Calibration & $\begin{array}{c}\text { Cross- } \\
\text { validation }\end{array}$ & Prediction & Calibration & $\begin{array}{c}\text { Cross- } \\
\text { validation }\end{array}$ & Prediction \\
\hline & RMSE (\%) & 2.35 & 2.35 & 3.21 & 2.59 & 2.59 & 3.74 \\
\hline & Bias (\%) & -0.19 & -0.01 & 0.12 & 0.00 & $5.61 \times 10^{-5}$ & -3.61 \\
\hline & $\mathrm{RE}(\%)$ & 10.21 & - & 12.14 & 11.09 & - & 14.48 \\
\hline & $\mathrm{R}^{2}$ & 0.959 & 0.964 & 0.926 & 0.951 & 0.951 & 0.991 \\
\hline & $t$-test* & - & - & 2.774 & - & - & 2.306 \\
\hline & F-test* & - & - & 1.120 & - & - & 1.051 \\
\hline SVR & RMSE (\%) & 0.43 & 5.99 & 3.85 & 0.63 & 5.08 & 5.56 \\
\hline & Bias (\%) & 0.104 & 0.03 & -2.99 & -0.22 & -1.26 & 3.16 \\
\hline & RE (\%) & 2.00 & - & 11.18 & 3.26 & - & 19.99 \\
\hline & $\mathrm{R}^{2}$ & 0.999 & 0.714 & 0.988 & 0.998 & 0.784 & 0.999 \\
\hline & $t$-test* & - & - & 2.446 & - & - & 2.776 \\
\hline & F-test * & - & - & 0.999 & - & - & 1.028 \\
\hline
\end{tabular}

296 The PLS model for MIR data shows satisfactory performance for quantifying the kerosene content in the

297 adulterated samples, with a root mean square error of cross-validation (RMSECV) and prediction (RMSEP) equal to

$2982.35 \%$ and $3.21 \%$, respectively. Additionally, the model shows to be linear in the concentration range $\left(\mathrm{R}^{2}=0.947\right)$.

299 Similar results are observed for NIR data, where the RMSECV and RMSEP were respectively equal to $2.59 \%$ and

$3003.74 \%$. The growth in the residues is associated with the higher complexity of NIR data in comparison with MIR.

301 The NIR spectra are composed of superposed overtone and combinations bands; whereas the MIR spectra are

302 associated to fundamental vibration modes of the samples' constituents, therefore being more sensible [6]. The

303 SVR-NIR model presents a constant variance and low residues for both calibration and prediction samples, with a

304 root mean square error of cross-validation (RMSECV) and prediction (RMSEP) equal to 5.07\% and 5.56\%,

305 respectively, and a determination coefficient of 0.999. The same behavior occurs in SVR-MIR, where the RMSECV

306 and RMSEP were equal to $3.85 \%$ and $5.99 \%$, respectively, in addition to a determination coefficient of 0.988 , which

307 indicates good fit throughout the analytical ranges for both methods.

308 The values of calibration, cross-validation and prediction errors obtained for this methodology are close to those

309 observed in the literature for quantifying kerosene in diesel by another spectroscopic technique [46]. Results of

310 paired t-tests and F-tests (Table 3) confirm that predicted concentrations were statistically equal to the reference

311 concentrations and all the calibration models used in this work are valid for a confidence level of $95 \%$. The low

312 RMSE values and the high correlation coefficients demonstrate that these PLS models may be applied to quantify 
313 kerosene volumetric concentration in diesel for controlling adulteration issues. Fig. 3 depicts the elliptical joint 314 confidence region (EJCR) at 95\% confidence level for the slope and intercept of the regression line in predicted 315 versus reference values. The ellipse contains the ideal point $(1,0)$ for slope and intercept, respectively, showing that 316 the reference and predicted values are not significantly different at 95\% confidence level for PLS-MIR, PLS-NIR, 317 SVR-NIR and SVR-MIR; thus, no systematic errors were detected in calibration.
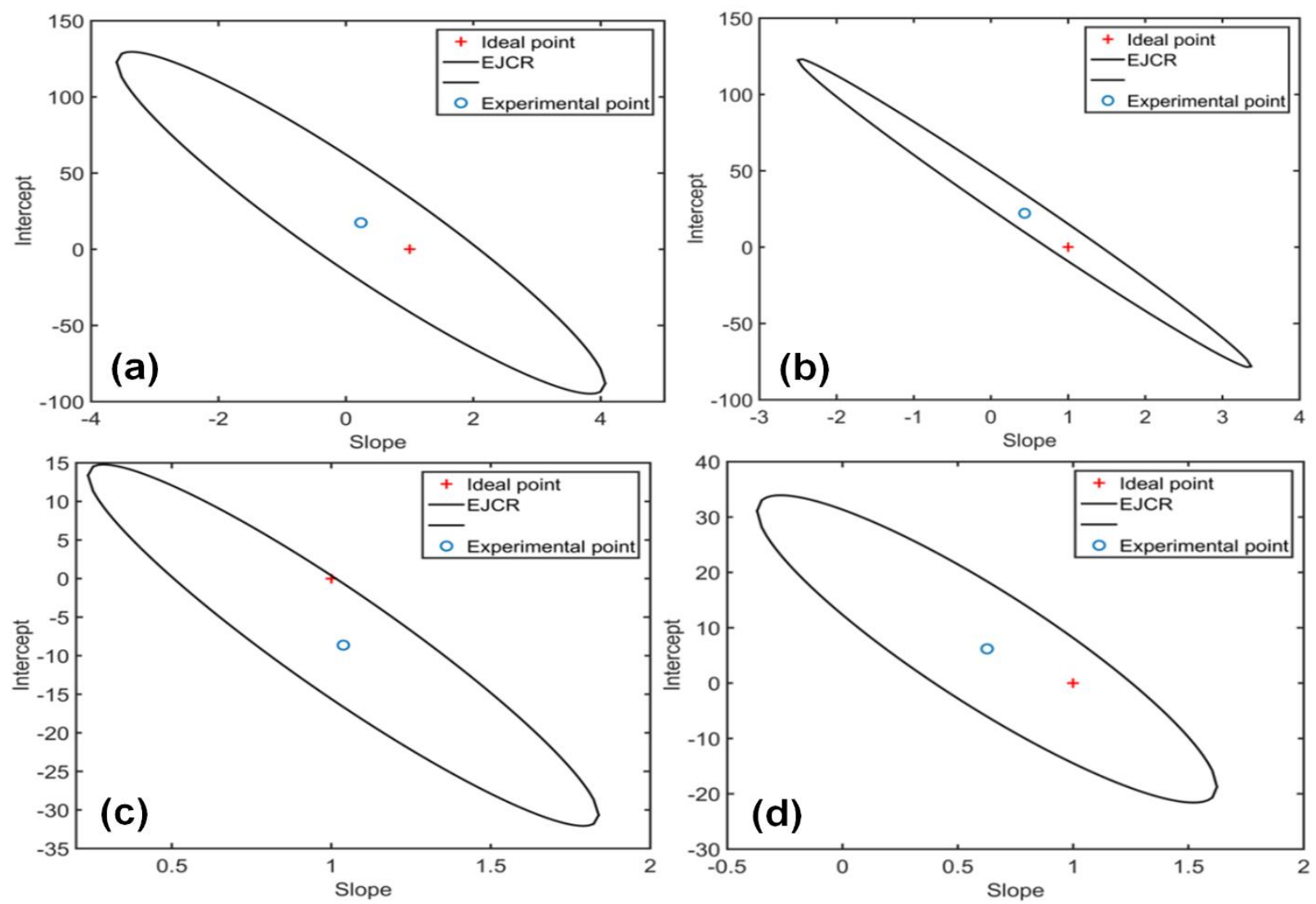

Fig. 3. EJCR for the calibrations models to quantifying kerosene with (a) PLS-MIR, (b) SVR-MIR, (c) PLS-NIR 320 and (d) SVR-NIR.

MCR-ALS was also applied to these data; however, it was not possible to quantify the concentration of kerosene with IR spectroscopy due to the non-correlation between samples. A low correlation coefficient and high errors were obtained for MIR, such as RMSEC and $\mathrm{R}^{2}$ of $20.79 \%$ and 0.470 , respectively. Meanwhile, the recovered spectral profile (Sopt) of the adulterant could be calculated and is shown in Fig. 4a. 

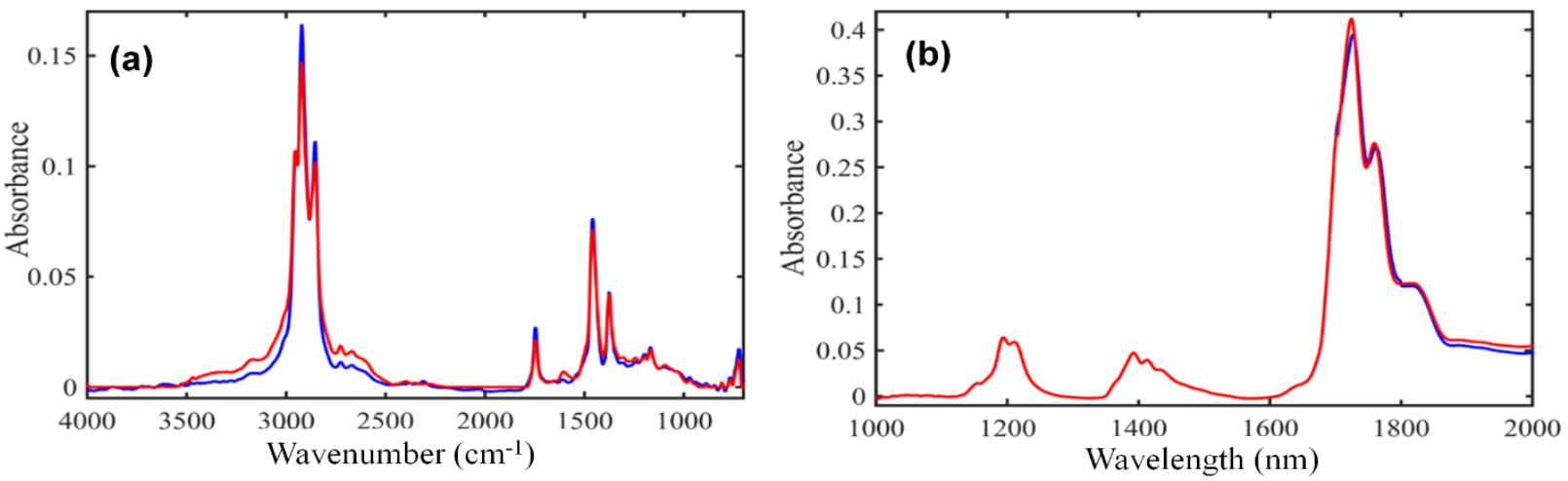

Fig. 4. Comparison between the original IR spectra (blue) and the Sopt obtained by MCR-ALS (red) for kerosene solvent using (a) MIR and (b) NIR data.

The model was able to recover 3 Sopts, where Sopt1, Sopt 2 and Sopt 3 are the recovered profiles of diesel S10,

331 kerosene and biodiesel, respectively, identifying the adulterant spectra despite the high chemical similarity between 332 diesel and kerosene. This can be concluded because of the similarity between the spectral profiles and Sopts,

333 presenting only a small difference in some band intensities due to the resemblance among the fuel and the adulterant.

334 MCR-NIR presented lower RMSEC and higher $\mathrm{R}^{2}$ values than MCR-MIR (15.94\% and 0.620, respectively). These 335 results indicate better precision in the quantification process; meanwhile, this model is not reliable for quantifying

336 kerosene content and may only be used for the Sopt recuperation (Fig. 4b). It was possible to recover two spectral 337 profiles (Sopt1 and Sopt2), corresponding to the diesel/biodiesel blend and kerosene, respectively.

338 Correlation analysis $\left(\mathrm{R}^{2}\right)$ between kerosene spectra and the recovered profile was also performed and showed the 339 resemblance among them. The $\mathrm{R}^{2}$ was of 0.977 and 0.990 for MCR-MIR and MCR-NIR. This method can be 340 interesting to solve the big issue of identifying kerosene adulteration in commercial diesel, along with PLS and SVR 341 calibration to efficiently quantify its content.

\section{Multivariate Classification for Fuel Aging}

344 By applying PCA to the preprocessed data, three PCs (87.53\% of explained variance) were selected for MIR and 345 three PCs (96.67\% of explained variance) for NIR. Fig. 5 depicts the scores graph for the PCA models without LDA. 346 The scores graph that best separated the sample classes under and over 30 days of storage in PCA was built using 347 PC2 x PC3 for MIR and PC1 x PC2 for NIR (Fig. 5a and 5b). PCA was able to separate the samples with aging time 
over and under 30 days of storage using MIR spectral data (Fig. 5a), detecting some compositional differences caused by the aging process to distinguish both classes. For NIR (Fig. 5b), group distribution was not satisfactory

350 just with the exploratory analysis. Since PCA is used to get a view of the data in space and the important loadings 351 for each PC, LDA is needed for enabling an accurate classification of the samples.
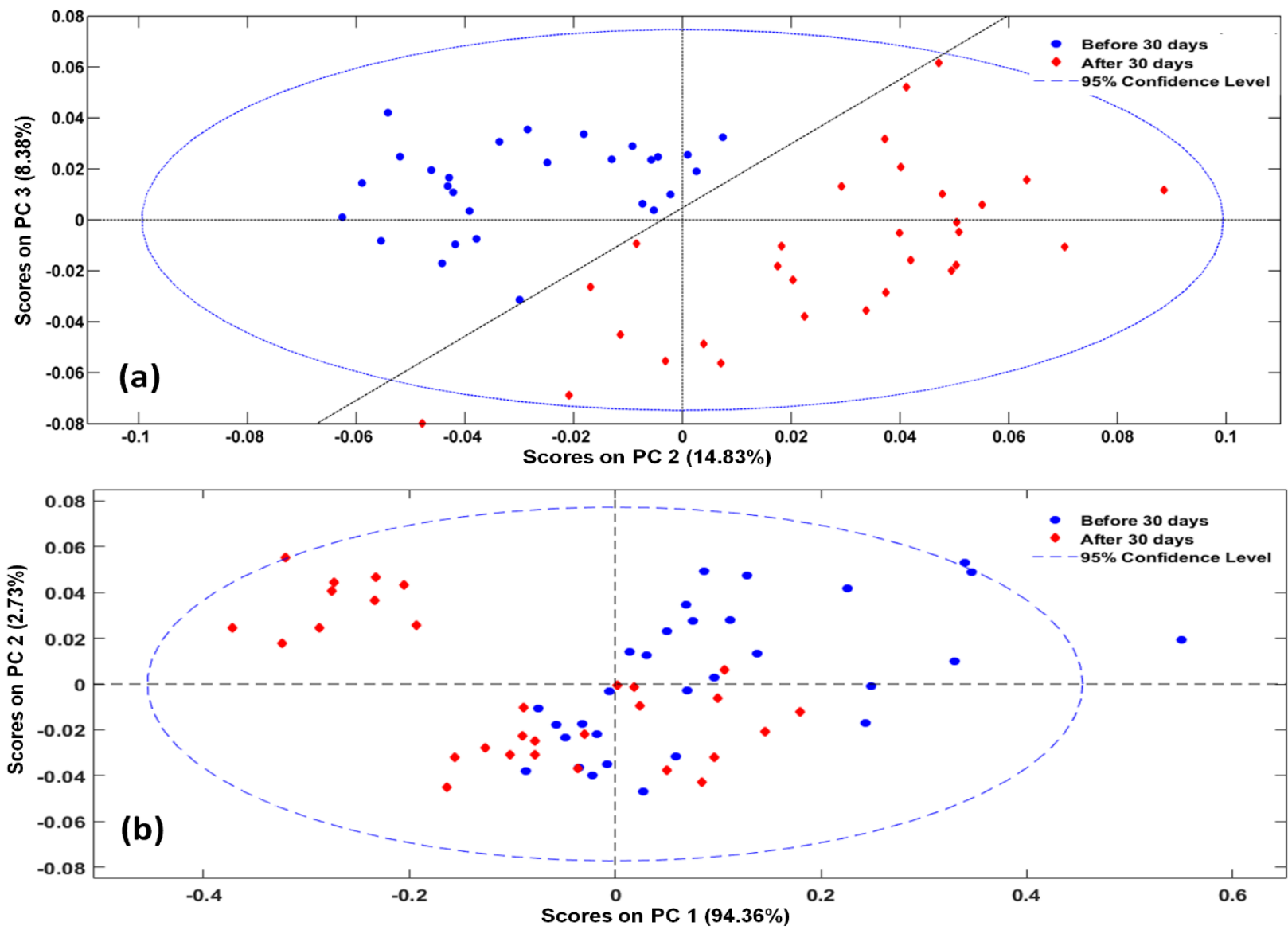

353 Fig. 5. Scores plot for (a) MIR and (b) NIR spectra analyzed by PCA.

The loadings profile of PCA-MIR model (Fig. 6) depicts the absorption features of the IR spectra that most influenced the segregation between the sample classes. The coefficients that most influenced PC1 were wavenumbers at $1740 \mathrm{~cm}^{-1}, 1196 \mathrm{~cm}^{-1}$ and $1168 \mathrm{~cm}^{-1}$, referent to biodiesel absorption bands (see Fig. 2a). This occurs since biodiesel is composed of esters, which have different spectroscopic characteristics than the hydrocarbons present in diesel and kerosene. Thus, the pattern recognition model was able to detect the influence of kerosene by the changes in biodiesel content into the blends. It can be proposed that PC1 was able to identify the 
the samples, as predicted by PetroOxy results. PC2 and PC3 were more influenced by wavenumbers that correspond

363 to compounds that may have been produced in the degradation of the blends, such as aldehydes, phenols and amides

364 (see Table 4), which justifies the good separation of classes with different storage times in the PCA scores (Fig. 5a).
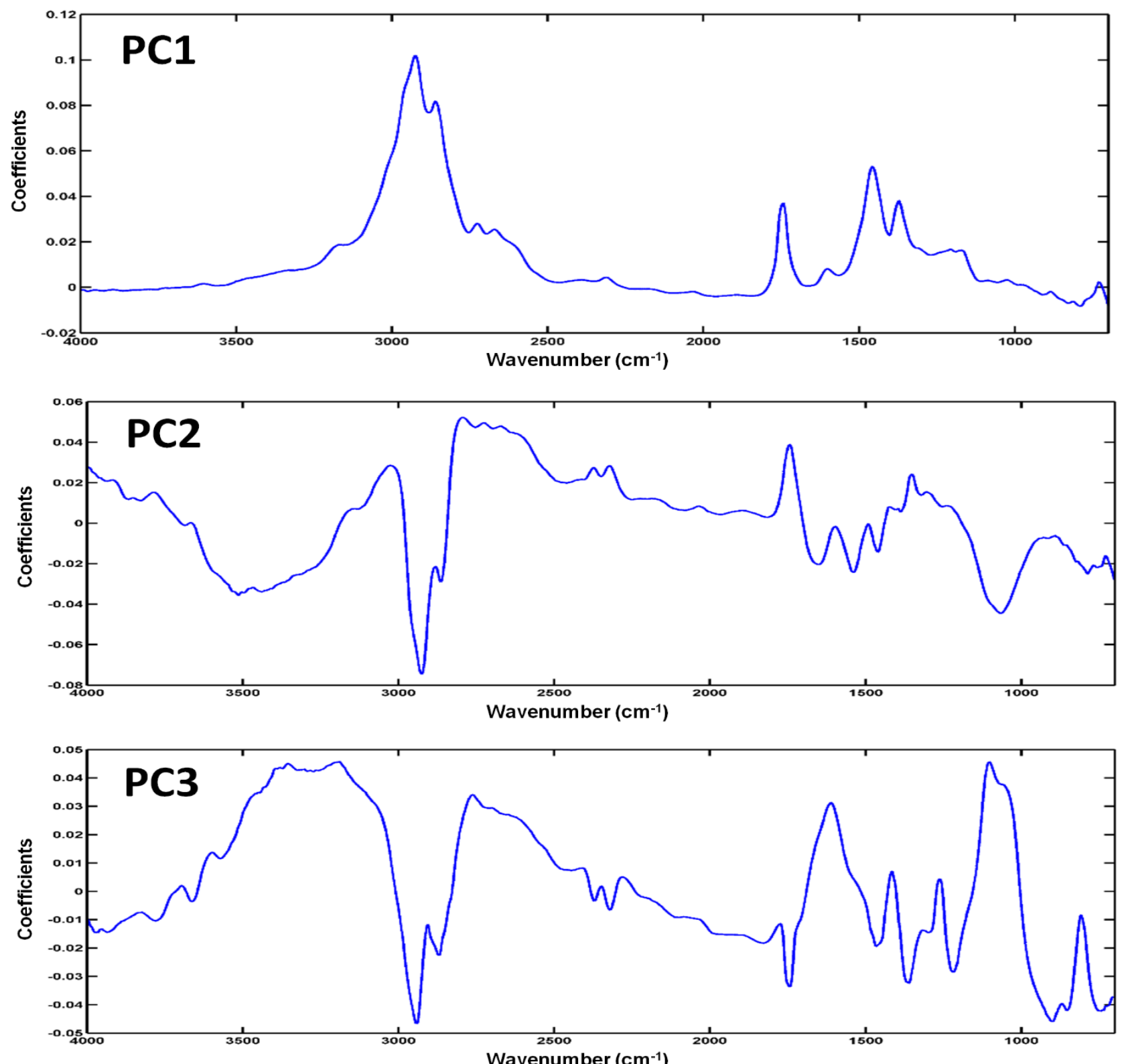

366 Fig. 6. PCA loadings profile for MIR. 
371 Table 4. Absorption features that most influenced PC2 and PC3 in MIR loadings.

\begin{tabular}{|c|c|c|c|}
\hline \multicolumn{2}{|c|}{ Positive coefficients of $\mathrm{PC} 2$} & \multicolumn{2}{|c|}{ Negative coefficients of $\mathrm{PC} 2$} \\
\hline Wavenumber $\left(\mathrm{cm}^{-1}\right)$ & Vibration & Wavenumber $\left(\mathrm{cm}^{-1}\right)$ & Vibration \\
\hline $3070-3010$ & Aromatic $v(\mathrm{C}-\mathrm{H})$ & 3500 & $\mathrm{O}-\mathrm{H}$ \\
\hline $2800-2700$ & Aldehyde $v(\mathrm{C}-\mathrm{H})$ & 2921 & $\mathrm{v}(\mathrm{C}-\mathrm{H})$ of $\mathrm{CH}_{2}$ \\
\hline \multirow[t]{3}{*}{$1800-1700$} & $v(\mathrm{C}=\mathrm{O})$ & 2853 & $v(\mathrm{C}-\mathrm{H})$ of $\mathrm{CH}_{2}$ \\
\hline & & $1600-1450$ & Aromatic $v(C=C)$ \\
\hline & & $1060-1020$ & $v(\mathrm{C}=\mathrm{S})$ or $v(\mathrm{~S}=\mathrm{O})$ \\
\hline \multicolumn{2}{|c|}{ Positive coefficients of PC3 } & \multicolumn{2}{|c|}{ Negative coefficients of PC3 } \\
\hline Wavenumber $\left(\mathrm{cm}^{-1}\right)$ & Vibration & Wavenumber $\left(\mathrm{cm}^{-1}\right)$ & Vibration \\
\hline 3300 & $\begin{array}{c}\text { Carboxylic acid } v(\mathrm{O}-\mathrm{H}) \text { or amide } \\
\qquad(\mathrm{N}-\mathrm{H})\end{array}$ & 2921 & $v(\mathrm{C}-\mathrm{H})$ of $\mathrm{CH}_{2}$ \\
\hline $2800-2700$ & Aldehyde $v(\mathrm{C}-\mathrm{H})$ & 2853 & $v(\mathrm{C}-\mathrm{H})$ of $\mathrm{CH}_{2}$ \\
\hline $1560-1530$ & Amide $\delta(\mathrm{N}-\mathrm{H})$ and $v(\mathrm{C}-\mathrm{N})$ & $1800-1700$ & $v(\mathrm{C}=\mathrm{O})$ \\
\hline $1060-1020$ & $v(\mathrm{~S}=\mathrm{O})$ & 1250 & $v(\mathrm{C}-\mathrm{O})$ \\
\hline & & 722 & $\rho_{a s}(\mathrm{C}-\mathrm{H})$ of $\mathrm{CH}_{2}$ \\
\hline
\end{tabular}

374 In PCA-LDA, 10 PCs were selected for MIR and NIR (96.53\% and 97.87\% of explained variance, respectively)

375 to classify the data according to its storage time (over and under 30 days of storage). SPA and GA algorithms

376 provide a set of selected variables that promotes the higher inter-class segregation to be used in LDA. The selected

377 variables for both SPA and GA are shown in Table 5. All the discriminant function (DF) plots for the models are 378 presented on Online Resource 2. 
Table 5. SPA and GA selected variables for MIR and NIR data.

\begin{tabular}{|c|c|c|}
\hline Spectroscopic technique & Model & Selected variables \\
\hline \multirow[t]{9}{*}{$\operatorname{MIR}\left(\mathrm{cm}^{-1}\right)$} & SPA $(34)^{a}$ & $\begin{array}{llllllll}698 & 745 & 779 & 810 & 854 & 907 & 999 & 1204\end{array}$ \\
\hline & & $\begin{array}{lllllll}1321 & 1360 & 1398 & 1422 & 1445 & 1485 & 1533\end{array}$ \\
\hline & & $\begin{array}{lllllll}1578 & 1663 & 1721 & 1748 & 1794 & 2280 & 2336\end{array}$ \\
\hline & & $\begin{array}{lllllll}2791 & 2886 & 2938 & 2959 & 3005 & 3518 & 3545\end{array}$ \\
\hline & & $\begin{array}{lllll}3651 & 3686 & 3794 & 3906 & 3998\end{array}$ \\
\hline & $\mathrm{GA}(26)^{\mathrm{a}}$ & $\begin{array}{lllllll}1022 & 1047 & 1059 & 1092 & 1142 & 1167 & 1254\end{array}$ \\
\hline & & $\begin{array}{lllllll}1346 & 1416 & 1528 & 1744 & 1746 & 2045 & 2095\end{array}$ \\
\hline & & $\begin{array}{lllllll}2253 & 2452 & 2675 & 2806 & 2860 & 2997 & 3009\end{array}$ \\
\hline & & $\begin{array}{lllll}3096 & 3406 & 3688 & 3711 & 3993\end{array}$ \\
\hline \multirow[t]{9}{*}{ NIR (nm) } & SPA $(31)^{\mathrm{a}}$ & $\begin{array}{llllllll}922 & 925 & 928 & 934 & 941 & 946 & 953 & 957\end{array}$ \\
\hline & & $\begin{array}{llllllll}964 & 966 & 973 & 983 & 987 & 997 & 1008 & 1017\end{array}$ \\
\hline & & $\begin{array}{lllllll}1026 & 1035 & 1048 & 1095 & 1139 & 1238 & 1387\end{array}$ \\
\hline & & $\begin{array}{lllllll}1411 & 1673 & 1689 & 1705 & 1765 & 1852 & 1926\end{array}$ \\
\hline & & 2133 \\
\hline & $\mathrm{GA}(27)^{\mathrm{a}}$ & $\begin{array}{lllllll}954 & 977 & 1033 & 1065 & 1096 & 1152 & 1154\end{array}$ \\
\hline & & $\begin{array}{lllllll}1160 & 1168 & 1244 & 1265 & 1309 & 1340 & 1356\end{array}$ \\
\hline & & $\begin{array}{lllllll}1378 & 1397 & 1437 & 1478 & 1528 & 1660 & 1696\end{array}$ \\
\hline & & $\begin{array}{llllll}1748 & 1799 & 1814 & 1833 & 1926 & 2108\end{array}$ \\
\hline
\end{tabular}

390 As also seen in PCA loadings (Table 4) for the model with good aging classification before applying LDA (PCA-

391 MIR), some of the SPA and GA selected variables for MIR and NIR are related to biodiesel content $\left(\sim 1748 \mathrm{~cm}^{-1}\right.$ for

392 MIR and $2133 \mathrm{~nm}$ for NIR, for example)and probable products of sample degradation, such as aldehydes (1700-

$3931800 \mathrm{~cm}^{-1}$ for MIR), amides $\left(\sim 1530 \mathrm{~cm}^{-1}\right.$ for MIR and $\sim 1430 \mathrm{~nm}$ for NIR) and carboxylic acids $\left(\sim 1700 \mathrm{~cm}^{-1}\right.$ for

394 MIR and $~ 1920 \mathrm{~nm}$ for NIR) [43,47]. After this selection, LDA was applied in order to classify the samples into 395 their correct classes. Sensitivity (Sens), specificity (Spec) and correct classification (CC) were calculated in order to 396 infer the prediction performance for these models. Table 6 summarizes the results for figures of merit for the 397 classification models. PCA-LDA and SPA-LDA reached 100\% accuracy with both IR methods; although GA-LDA 398 presented some lower results of sensitivity and correct classification for the sample class before 30 days of storage, 399 its efficiency was still satisfactory $(>85.7 \%)$. 
401 models.

\begin{tabular}{ccccc}
\hline Spectroscopic technique & FOM & PCA-LDA & SPA-LDA & GA-LDA \\
\hline MIR & Before 30 days & & 100.0 & 85.7 \\
& Sens (\%) & 100.0 & 100.0 & 100.0 \\
Spec (\%) & 100.0 & 100.0 & 91.6 \\
CC (\%) & 100.0 & & \\
& After 30 days & & 100.0 & 100.0 \\
Sens (\%) & 100.0 & 100.0 & 100.0 \\
Spec (\%) & 100.0 & 100.0 & 100.0 \\
CC (\%) & 100.0 & & 85.7 \\
& Before 30 days & & 100.0 & 100.0 \\
& Sens (\%) & 100.0 & 100.0 & 91.6 \\
Spec (\%) & 100.0 & 100.0 & 100.0 \\
& CC (\%) & 100.0 & 100.0 & 100.0 \\
\hline
\end{tabular}

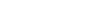

403 These results show that PCA-LDA, SPA-LDA and GA-LDA models for both IR spectroscopies are capable of

404 differentiating the monthly storage time of these fuels with good accuracy, unlike what can be observed in the

405 physicochemical analysis results during storage, which were not able to detect changes in diesel-biodiesel samples

406 with or without kerosene during the monitoring. Furthermore, NIR data can be recorded by portable instruments,

407 enabling faster "in loco" inspection procedures with an effective and simple methodology with the combined

408 classification models. PCA loadings detected the presence of adulteration by observing variations on biodiesel

409 concentration, in addition to detect chemical species from decomposition reactions of the diesel-biodiesel-kerosene

410 mixtures as the main features responsible for aging class separation, as well as SPA and GA selected variables.

411

\section{Conclusions}

413 The NIR and MIR spectra coupled to PLS and SVR models for quantifying kerosene content presented low RMSE

414 values and high correlation between real and predicted concentrations, in spite of the similar chemical composition 
415 of diesel and kerosene. MCR-ALS with correlation constraint was able to identify and recover the spectral profile of 416 commercial diesel and kerosene adulterant from the IR spectra of contaminated blends.

417 PCA-LDA, SPA-LDA and GA-LDA enabled correctly classifying diesel-biodiesel with kerosene in different 418 degradation levels, separating these samples into two well-defined groups under and over thirty days of storage. The 419 method was highly accurate and reliable for evaluating fuel storage stability. PCA loadings, as well as GA and SPA

420 selected variables, detected that spectroscopic features related to degradation products such as amides, carboxylic 421 acids and aldehydes were responsible for the classification by aging stage.

422 The multivariate classification methodology developed in this paper is an efficient tool for classifying commercial 423 diesel with kerosene adulterant by aging time and chemically observe the degradation phenomenon. Combining 424 MCR-ALS with PLS or SVR models is powerful to solve the great issue in quantifying and identifying this 425 adulteration, being interesting to improve the investigative process of adulteration in diesel fuel screening. The 426 results of the study that we performed demonstrated good results in the quantification using these techniques. 427 However, more in-depth studies with more sampling need to be performed in order to have a better validation of the 428 technique and to be more certain. However, our results are encouraging. The evaluation method is simple, fast, does 429 not require pretreatment of the samples, may be carried out "in loco" with portable NIR instruments and is low cost.

\section{Acknowledgements}

432 The authors acknowledge the support provided by the Post-Graduate Chemistry Program PPGQ/UFRN, the 433 Energetic Technologies Laboratory (LTEN), the Biological Chemistry and Chemometrics Group, the CAPES and 434 CNPQ - Brazil for the financial support.

\section{Conflict of Interest}

437 The authors declare that they have no conflict of interest.

\section{References}

440 [1] Obeidat SM, Al-Ktash MM, Al-Momani IF. Study of fuel assessment and adulteration using EEMF and 441 multiway PCA. Energy Fuels. 2014; https://doi.org/10.1021/ef500718e [CrossRef] [Google Scholar] 
442 [2] Krakowska B, Stanimirova I, Orzel J, Daszykowski M, Grabowski I, Zaleszczyk G, Sznajder M. Detection 443 of discoloration in diesel fuel based on gas chromatographic fingerprints. Anal Bioanal Chem. 2015; 444 https://doi.org/10.1007/s00216-014-8332-4 [CrossRef] [Google Scholar]

445 [3] Agência Nacional do Petróleo, Gás Natural e Biocombustíveis - ANP. Resolução No. 3 de 08.02.2007. In: 446 DOU 09.02.2007. http://legislacao.anp.gov.br/?path=legislacao-anp/resol-anp/2007/fevereiro\&item=ranp-3--

$447 \quad$ 2007\&export=pdf. Accessed in 20 Oct 2018.

448 [4] Menezes EW, Silva R, Cataluña R, Ortega RJC. Effect of ethers and ether/ethanol additives on the 449 physicochemical properties of diesel fuel and on engine tests. Fuel. 2006; https://doi.org/10.1016/j.fuel.2005.08.027 450 [CrossRef] [Google Scholar]

451 [5] Agência Nacional do Petróleo, Gás Natural e Biocombustíveis - ANP. Resolução No. 30 de 23.06.2016. In: 452 DOU 24.06.2016.

453 http://www.lex.com.br/legis_27160107_RESOLUCAO_N_30_DE_23_DE_JUNHO_DE_2016.aspx. Accessed in 45420 Oct 2018.

455 [6] Câmara ABF, de Carvalho LS, Morais CLM, Lima LAS, Araújo HOM, Oliveira FM, Lima KMG. MCR456 ALS and PLS coupled to NIR/MIR spectroscopies for quantification and identification of adulterant in biodiesel457 diesel blends. Fuel. 2017; https://doi.org/10.1016/j.fuel.2017.08.072 [CrossRef] [Google Scholar]

458 [7] Cunha IBS, Fernandes AMAP, Tega DU, Simas RC, Nascimento HL, Sá GF, Daroda RJ, Eberlin MN, 459 Alberici RM. Quantitation and quality control of biodiesel/petrodiesel (Bn) blends by easy ambient sonic-spray 460 ionization mass spectrometry. Energy Fuels. 2012; https://doi.org/10.1021/ef3010866 [CrossRef] [Google Scholar]

461 [8] Gotor R, Tiebe C, Schilischka J, Bell J, Rurack K. Detection of adulterated diesel using fluorescent test 462 strips and smartphone readout. Energy Fuels. 2017; https://doi.org/10.1021/acs.energyfuels.7b01538 [CrossRef]

\section{3 [Google Scholar]}

464 [9] Jose TK, Anand K. Effects of biodiesel composition on its long term storage stability. Fuel. 2016; 465 https://doi.org/10.1016/j.fuel.2016.03.007 [CrossRef] [Google Scholar]

466 [10] Brereton RG, Jansen J, Lopes J, Marini F, Pomerantsev A, Rodionova O, Roger JM, Walczak B, Tauler R. 467 Chemometrics in analytical chemistry - part II: modeling, validation, and applications. Anal Bioanal Chem. 2018; 468 https://doi.org/10.1007/s00216-018-1283-4 [CrossRef] [Google Scholar] 
470 total reflectance Fourier transform infrared (ATR-FTIR) spectral prediction of postmortem interval from vitreous

471 humor samples. Anal Bioanal Chem. 2018; https://doi.org/10.1007/s00216-018-1367-1 [CrossRef] [Google Scholar]

472 [12] Aboualizadeh E, Ranji M, Sorenson CM, Sepehr R, Sheibani N, Hirschmugl CJ. Retinal oxidative stress at

473 the onset of diabetes determined by synchrontron FTIR widefield imaging: towards diabetes pathogenesis. Analyst.

474 2017; https://doi.org/10.1039/c6an02603f [CrossRef] [Google Scholar]

475 [13] Theophilou G, Morais CLM, Halliwell DE, Lima KMG, Drury J, Martin-Hirsch PL, Stringfellow HF, 476 Hapangama DK, Martin FL. Synchrotron- and focal plane array-based Fourier-transform infrared spectroscopy

477 differentiates the basalis and functionalis epithelial endometrial regions and identifies putative stem cell regions of 478 human endometrial glands. Anal Bioanal Chem. 2018; https://doi.org/10.1007/s00216-018-1111-x [CrossRef] 479 [Google Scholar]

480 [14] Marques AS, Moraes EP, Júnior MAA, Moura AD, Neto VFA, Neto RM, Lima KMG. Rapid 481 discrimination of klebsiella pneumoniae carbapenemase $2-$ producing and non-producing klebsiella 482 pneumoniae strains using near-infrared spectroscopy (NIRS) and multivariate analysis. Talanta. 2015; 483 https://doi.org/10.1016/j.talanta.2014.11.006 [CrossRef] [Google Scholar]

484 [15] Hu J, Ma X, Liu L, Wu Y, Ouyang J. Rapid evaluation of the quality of chestnuts using near-infrared 485 reflectance spectroscopy. Food Chem. 2017; https://doi.org/10.1016/j.foodchem.2017.03.127 [CrossRef] [Google 486 Scholar]

487 [16] Corgozinho CNC, Pasa VMD, Barbeira PJS. Determination of residual oil in diesel oil by 488 spectrofluorimetric and chemometric analysis. Talanta. 2008; https://doi.org/10.1016/j.talanta.2008.03.003 489 [CrossRef] [Google Scholar]

490 [17] Thissen U, Pepers M, Ustun B, Melssen WJ, Buydens LMC. Comparing support vector machines to PLS 491 for spectral regression applications. Chem Intell Lab Syst. 2004; https://doi.org/10.1016/j.chemolab.2004.01.002 492 [CrossRef] [Google Scholar]

493 [18] Dantas WFC, Alves JCL, Poppi RJ. MCR-ALS with correlation constraint and Raman spectroscopy for 494 identification and quantification of biofuels and adulterants in petroleum diesel. Chemom Intell Lab Syst. 2017; 495 https://doi.org/10.1016/j.chemolab.2017.04.002 [CrossRef] [Google Scholar] 
496 [19] de Juan A, Tauler R. Multivariate curve resolution (MCR) from 2000: progress in concepts and 497 applications. Crit Rev Anal Chem. 2006; https://doi.org/10.1080/10408340600970005 [CrossRef] [Google Scholar]

498 [20] ASTM D 7545-14. Standard test method for oxidation stability of middle distillate fuels - rapid small scale

499 oxidation test (RSSOT). In: West Conshohocken (PA): ASTM International. 2014;

500 https://www.astm.org/Standards/D7545.htm. Accessed 23 Oct 2018.

501 [21] ASTM D 86-12. Standard test method for distillation of petroleum products at atmospheric pressure. In:

502 West $\quad$ Conshohocken $\quad$ PA): 2013 ;

503 https://www.astm.org/DATABASE.CART/HISTORICAL/D86-12.htm. Accessed 23 Oct 2018.

504 [22] ASTM D 7042-14. Standard test method for dynamic viscosity and density of liquids by Stabinger

505 viscometer (and the calculation of kinematic viscosity). In: West Conshohocken (PA): ASTM International. 2014;

506 https://www.astm.org/DATABASE.CART/HISTORICAL/D7042-14.htm. Accessed 23 Oct 2018.

507 [23] ASTM D 2500-11. Standard test method for cloud point of petroleum products. In: West Conshohocken

508 (PA): ASTM International. 2011; https://www.astm.org/DATABASE.CART/HISTORICAL/D2500-11.htm.

509 Accessed 23 Oct 2018.

510 [24] Kennard RW, Stone LA. Computer aided design of experiments. Technometrics. 1969;

511 https://doi.org/10.2307/1266770 [CrossRef] [Google Scholar]

512 [25] Bro R, Smilde AK. Principal component analysis. Anal. Methods. 2014; 513 https://doi.org/10.1039/C3AY41907J [CrossRef] [Google Scholar]

514 [26] Eftekhari A, Forouzanfar M, Moghaddam HA, Alirezaie J. Block-wise 2D kernel PCA/LDA for face 515 recognition. Inform Process Lett. 2010; https://doi.org/10.1016/j.ipl.2010.06.006 [CrossRef] [Google Scholar]

516 [27] Pontes MJC, Galvão RKH, Araújo MCU, Moreira PNT, Neto ODP, José GE, Saldanha TCB. The 517 successive projections algorithm for spectral variable selection in classification problems. Chemom Intell Lab Syst. 518 2005; https://doi.org/10.1016/j.chemolab.2004.12.001 [CrossRef] [Google Scholar]

519 [28] Broadhursta D, Goodacrea R, Jones A, Rowland JJ, Kell DB. Genetic algorithms as a method for variable 520 selection in multiple linear regression and partial least squares regression, with applications to pyrolysis mass 521 spectrometry. Anal Chim Acta. 1997; https://doi.org/10.1016/S0003-2670(97)00065-2 [CrossRef] [Google Scholar] 522 [29] Dixon SJ, Brereton RG. Comparison of performance of five common classifiers represented as boundary 523 methods: Euclidean distance to centroids, linear discriminant analysis, quadratic discriminant analysis, learning 
524 vector quantization and support vector machines, as dependent on data structure. Chemometr Intell Lab Syst. 2009;

525 https://doi.org/10.1016/j.chemolab.2008.07.010 [CrossRef] [Google Scholar]

526 [30] Wu W, Mallet Y, Walczak B, Penninckx W, Massart DL, Heuerding S. Erni F. Comparison of regularized 527 discriminant analysis, linear discriminant analysis and quadratic discriminant analysis. Applied to NIR data. Anal 528 Chim Acta 1996; https://doi.org/10.1016/0003-2670(96)00142-0 [CrossRef] [Google Scholar]

529 [31] Geladi P, Kowalski BR. Partial least-squares regression: a tutorial. Anal. Chim. Acta. 1986; 530 https://doi.org/10.1016/0003-2670(86)80028-9 [CrossRef] [Google Scholar]

531 [32] Smola AJ, Schölkopf B. A tutorial on support vector regression. Stat. Comput. 2004; 532 https://doi.org/10.1023/B:STCO.0000035301.49549.88 [CrossRef] [Google Scholar]

533 [33] Alves JCL, Henriques CB, Poppi RJ. Determination of diesel quality parameters using support vector 534 regression and near infrared spectroscopy for an in-line blending optimizer system. Fuel. 2012; 535 https://doi.org/10.1016/j.fuel.2012.03.016 [CrossRef] [Google Scholar]

536 [34] Tauler R, Kowaslki B, Fleming S. Multivariate curve resolution applied to spectral data from multiple runs 537 of an industrial process. Anal Chem. 1993; https://doi.org/10.1021/ac00063a019 [CrossRef] [Google Scholar]

538 [35] Jaumot J, Igne B, Anderso CA, Drennen JK, de Juan A. Blending process modeling and control by 539 multivariate curve resolution. Talanta. 2013; https://doi.org/10.1016/j.talanta.2013.09.037 [CrossRef] [Google 540 Scholar]

541 [36] Bro R, de Jong S. A fast non-negativity-constrained least squares algorithm. J Chemom. 1997; 542 https://doi.org/10.1002/(SICI)1099-128X(199709/10)11:5<393::AID-CEM483>3.0.CO;2-L [CrossRef] [Google 543 Scholar]

544 [37] Olivieri AC, Faber NM, Ferré J, Boqué R, Kalivas JH. Mark, H. Uncertainty estimation and figures of 545 merit for multivariate calibration. Pure Appl Chem. 2006; https://doi.org/10.1351/pac200678030633 [CrossRef] 546 [Google Scholar]

547 [38] Botella L, Bimbela F, Martin L, Arauzo J, Sanchez JL. oxidation stability of biodiesel fuels and blends 548 using the Rancimat and PetroOxy methods. Effect of 4-allyl-2,6-dimetoxiphenol and cathecol as biodiesel additives 549 on oxidation stability. Front Chem. 2014; https://doi.org/10.3389/fchem.2014.00043 [CrossRef] [Google Scholar]

550 [39] Karavalakis G, Stournas S, Karonis D. Evaluation of the oxidation stability of diesel/biodiesel blends. Fuel. 551 2010; https://doi.org/10.1016/j.fuel.2010.03.041 [CrossRef] [Google Scholar] 
552 [40] Roy MM, Wang W, Alawi M. Performance and emissions of a diesel engine fueled by biodiesel-diesel,

553 biodiesel-diesel-additive and kerosene-biodiesel blends. Energ Convers Manage. 2014;

554 https://doi.org/10.1016/j.enconman.2014.04.033 [CrossRef] [Google Scholar]

555 [41] Yadav SR, Murthy KV, Mishra D, Baral B. Estimation of petrol and diesel adulteration with kerosene and

556 assessment of usefulness of selected automobile fuel quality test parameters. IJEST. 2005;

557 https://doi.org/10.1007/BF03325839 [CrossRef] [Google Scholar]

558 [42] Ziegler K, Manka J. The effect of mixing diesel fuels additized with kerosene and cloud point depressants.

559 SAE Technical Paper 2000-01-2884. 2000; https://doi.org/10.4271/2000-01-2884 [CrossRef] [Google Scholar]

560 [43] Silverstein RM, Webster FX, Kiemle DJ. Spectrometric identification of organic compounds. 7th Ed. New

561 Jersey: Jonh Wiley \& Sons; 2005. [Google Scholar]

562 [44] Workman Jr, Weyer JL. Practical guide to interpretive near-infrared spectroscopy. 1st Ed. Boca Raton:

563 CRC Press; 2008. [Google Scholar]

564 [45] Yang C, Yang Z, Zhang G, Hollebone B, Landriault M, Wang Z, Lambert P, Brown CE. Characterization

565 and differentiation of chemical fingerprints of virgin and used lubricating oils for identification of contamination or

566 adulteration sources. Fuel. 2016; https://doi.org/10.1016/j.fuel.2015.09.070 [CrossRef] [Google Scholar]

567 [46] Divya O, Mishra AK. Multivariate methods on the excitation emission matrix fluorescence spectroscopic

568 data of diesel-kerosene mixtures: a comparative study. Anal Chim Acta. 2007;

569 https://doi.org/10.1016/j.aca.2007.03.079 [CrossRef] [Google Scholar]

570 [47] Monograph NIR spectroscopy. A guide to near-infrared spectroscopic analysis of industrial manufacturing

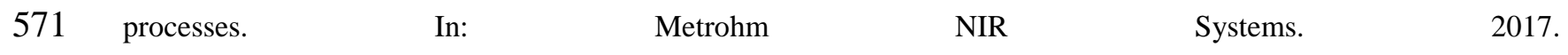

572 http://www.mep.net.au/wpmep/wpcontent/uploads/2013/05/MEP_Monograph_NIRS_81085026EN.pdf. Accessed

57329 Oct 2018. [CrossRef] [Google Scholar]

574

575 